\title{
Acknowledgement by Prof. Dr. Rainer Drath
}

This book was written in the second half of 2020. Ten years ago, AutomationML was a promising technology. Today AutomationML is a solution and offers more functionality and more solutions than is generally known.

The time is ripe for a textbook that explains the features and possibilities offered by AutomationML's Edition 2 and its hidden capabilities. While structuring this book project, the amount of material on Automation fundamentals and industry applications resulted in two books: first the present introduction into AutomationML principles and second a book for advanced users AutomationML - The Industrial Cookbook published by the same publisher.

This book provides researchers and industry partners a comprehensive in-depth look into the basics of AutomationML. It is remarkable that CAEX and AutomationML, even without any textbook so far, has surprisingly quickly found its way into the academic and industrial world. This book is intended to support this in greater depth.

This book was supported by valuable discussions with many AML experts and their contributions. I would like to take this opportunity to thank sincerely to Steffen Lips for his feedback in the geometry/kinematics modelling, to Nicole Schmidt and Arndt Lüder for the continuous tuning of the behaviour chapter, to Josef Prinz and Lorenz Hundt for the development, support and documentation of the AutomationML Editor, and to Pascal Habiger for manifold contributions to this book. And I want to thank Ronald Rosendahl for fruitful discussions about various perspectives of explaining AutomationML. It was a pleasure for me to formulate, collect, illustrate and compile all the topics and aspects of CAEX and AutomationML into a comprehensive book for the international scientific and industrial audience.

A special thanks goes to the mental and scientific roots of CAEX, Prof. Fay and Prof. Epple, who recognized the urgent topic of data exchange between engineering phases 20 years ago and initialized the CAEX development. It was my pleasure to drive the CAEX development starting 2001 together with Prof. Epple until its international standardization in 2006. In 2009, CAEX was adopted by the AutomationML association. I would also like to thank the head of the AutomationML office, Sven Schwirblat, for his support, and Carl Schumaker from Rockwell Automation in particular for his engaged support in smoothing the English language of this book.

Last but not least, I want to express my personal thanks to my wife Nicole Freitag, who, as an external reviewer, has also enriched the book with many valuable suggestions, and to my little son Jonathan, who is always a great source of inspiration.

Prof. Dr.-Ing. Rainer Drath, Kuppenheim, March 2021 Pforzheim University of Applied Sciences 
